\title{
A EDUCAÇÃO FORMAL INDÍGENA NO ÂMBITO DA EDUCAÇÃO PROFISSIONAL E TECNOLÓGICA (EPT)
}

\section{ARTIGO ORIGINAL}

PEREIRA, Jamilli Santos Martins ', OLIVEIRA, Cleber Macedo de 2, FECURY, Amanda Alves ${ }^{3}$, DENDASCK, Carla Viana ${ }^{4}$, DIAS, Claudio Alberto Gellis de Mattos ${ }^{5}$

PEREIRA, Jamilli Santos Martins. Et al. A educação formal indígena no âmbito da Educação Profissional e Tecnológica (EPT). Revista Científica Multidisciplinar Núcleo do Conhecimento. Ano. 07, Ed. 01, Vol. 05, pp. 47-59. Janeiro de 2022. ISSN: 2448-0959, Link de

acesso: https://www.nucleodoconhecimento.com.br/educacao/educacao-formalindigena

\footnotetext{
${ }^{1}$ Letróloga, Especialista em Educação Especial e Inclusiva, Discente do Programa de Pós-Graduação em Educação Profissional e Tecnológica (PROFEPT IFAP).

${ }^{2}$ Engenheiro Agrônomo, Especialista em Docência na Educação profissional e Tecnológica, Doutor em Entomologia, Professor e pesquisador do Instituto de Ensino Básico, Técnico e Tecnológico do Amapá (IFAP) e do Programa de Pós Graduação em Educação Profissional e Tecnológica (PROFEPT IFAP).

${ }^{3}$ Biomédica, Doutora em Doenças Tropicais, Professora e pesquisadora do Curso de Medicina do Campus Macapá, Universidade Federal do Amapá (UNIFAP).

${ }^{4}$ Teóloga, Doutora em Psicanálise Clínica. Atua há 15 anos com Metodologia Científica ( Método de Pesquisa) na Orientação de Produção Científica de Mestrandos e Doutorandos. Especialista em Pesquisas de Mercado e Pesquisas voltadas à área da Saúde. Doutoranda em Comunicação e Semiótica (PUC SP).

${ }^{5}$ Biólogo, Doutor em Teoria e Pesquisa do Comportamento, Professor e pesquisador do Curso de Licenciatura em Química do Instituto de Ensino Básico, Técnico e Tecnológico do Amapá (IFAP) e do Programa de Pós Graduação em Educação Profissional e Tecnológica (PROFEPT IFAP).
}

RC: 105315

Disponível em: https://www.nucleodoconhecimento.com.br/educacao/educacao-formalindigena 


\section{RESUMO}

A educação pode significar o elo entre os não Indígenas e os indígenas. A lei $12.711 / 2012$, versa sobre a obrigatoriedade da reserva de vagas nas universidades $e$ institutos federais, combinando frequência na escola pública com renda e etnia. A construção de cursos de educação profissional integrada à educação escolar indígena deve considerar os impasses, como também as potencialidades, na relação entre conhecimentos e práticas indígenas e os conhecimentos técnico-científicos, bem como a possibilidade de que os povos indígenas venham realmente a neles inscrever a sua própria perspectiva. O objetivo deste trabalho é discorrer sobre a educação formal indígena no âmbito da Educação Profissional e Tecnológica (EPT). Para tanto foi realizada uma pesquisa bibliográfica em língua portuguesa em bases de dados. A educação parece ser o caminho para a integração do indígena e sua formação para benefício próprio e da comunidade. A política de cotas ou de ações afirmativas é uma tentativa de diminuir a distância social quando se fala do acesso a vagas na educação, inclusive técnica. A existência de núcleos de estudos afro-brasileiros e indígenas parece, ainda que timidamente, contribuir com a pesquisa e divulgação sobre identidades e relações étnico-raciais, visando a diminuição da distância socioeducacional e das diferenças dentro das instituições. Apesar do preparo, ainda que em construção, das instituições para atender um público diverso como os indígenas, o acesso destes ainda é considerado pequeno.

Palavras-chave: Ensino, EPT, Educação Indígena, IFAP.

\section{INTRODUÇÃO}

A educação pode significar o elo entre os não indígenas e os indígenas numa busca por espaço, não no formato de guerra, mas de garantia de resistência e valorização.

O problema indígena não pode ser compreendido fora dos quadros da sociedade brasileira, mesmo porque só existe onde e quando índio e

RC: 105315

Disponível em: https://www.nucleodoconhecimento.com.br/educacao/educacao-formalindigena 
não-índio entram em contato. É, pois, um problema de interação entre etnias tribais e a sociedade nacional (RIBEIRO, 1989).

Para Darcy Ribeiro a educação é uma grande aliada no processo de formação e reconhecimento do povo indígena, uma educação em que o educando se enxergue e possa mudar o seu contexto, um auxílio, uma participação gradativa para com os demais de sua comunidade indígena

Em se tratando de povos indígenas no Brasil, observa-se que o contato dos nativos com os colonizadores europeus transformou a forma de esses povos conceberem sua educação. Hoje a educação formal e a educação informal são realizadas paralelamente e quase com igual importância dentro de muitas comunidades indígenas, sobretudo dentro daquelas que mantém maior contato com nãoindígenas (QUARESMA e FERREIRA, 2013).

\section{CAMINHOS PERCORRIDOS DA EDUCAÇÃO INDÍGENA NO BRASIL}

Muitas guerras e batalhas foram travadas, pois os indígenas apresentavam resistência à escolarização dos jesuítas e assim a educação escolar indígena começou a se concretizar somente a partir de 1945 (MENDES et al., 2017).

Com o advento da Constituição Federal (CF) de 1988, a educação escolar indígena se voltou para objetivos como: preservar a historicidade, a etnia e a cultura dos povos indígenas (BRASIL, 1988). Assim, a União se tornou responsável por oferecer e assegurar educação escolar indígena de qualidade e resguardar sua cultura, organização social, costumes, línguas, crenças, tradições e os direitos originários sobre suas terras, bem como a aplicação de metodologias de aprendizagem específicas para as populações indígenas (MENDES et al., 2017).

Sete anos após a promulgação da Constituição Federal, foi publicada a lei de diretrizes e bases da educação nacional (LDB), utilizando o termo educação escolar indígena, com base em igualdade social, bilinguismo, interculturalidade, historicidade de um povo, na preservação da língua materna, valorização étnica e de suas ciências e garantia a essas comunidades ao acesso à informação e conhecimento técnico-

RC: 105315

Disponível em: https://www.nucleodoconhecimento.com.br/educacao/educacao-formalindigena 
científico da sociedade nacional e internacional, indígena e não indígena (BRASIL, 1996). A LDB ratifica alguns direitos assegurados na Constituição Federal de 1988 como é apresentado na constituição, artigo 210 : "§ $2^{\circ} \mathrm{O}$ ensino fundamental regular será ministrado em língua portuguesa, assegurada às comunidades indígenas também a utilização de suas línguas maternas e processos próprios de aprendizagem" (BRASIL, 1988).

Em 1999, foi instituída as primeiras Diretrizes Curriculares Nacionais da Educação Escolar Indígena que fixaram normas para o funcionamento da educação básica indígena, definição e competência para oferta, tratava ainda sobre a formação de professores indígenas, currículo, flexibilização e liberdade pedagógica e curricular (BRASIL, 1999).

Posteriormente, em 2001, o Plano Nacional de Educação (PNE), com seus objetivos e metas outorgou aos estados a competência pela educação escolar indígena e tinha como objetivos a cooperação dos povos indígenas nas decisões de suas escolas e liberdade na construção do seu projeto político pedagógico, sendo assim, criada a categoria Escola Indígena (BRASIL, 2001).

No ano de 2012, houve a aprovação da Lei no 12.711/12, uma das políticas públicas utilizadas para a redução e enfrentamento das desigualdades étnicos raciais. A referida lei estabelece ainda medidas para ampliar o acesso dos segmentos mais pobres, dos negros e dos indígenas em universidades ligadas ao Ministério da Educação e instituições federais de ensino técnico de nível médio (BRASIL, 2012).

Ainda em conformidade com a lei de cotas, como é popularmente chamada a Lei $\mathrm{n}^{\circ}$ 12.711/12, as instituições federais de ensino superior deverão em cada seleção para ingresso, reservar no mínimo $50 \%$ de suas vagas para alunos que estudaram o ensino médio em escolas públicas e desta porcentagem $50 \%$ das vagas deve ser reservadas a alunos com renda familiar per capita até no máximo um salário mínimo e meio. O art. $4^{\circ}$ da lei versa que as instituições federais de ensino técnico de nível médio

RC: 105315

Disponível em: https://www.nucleodoconhecimento.com.br/educacao/educacao-formalindigena 
deverão reservar $50 \%$ de suas vagas em cada seleção de ingresso a alunos que estudaram o ensino fundamental em escolas públicas. Essas vagas deverão ser preenchidas por autodeclarados pretos, pardos, indígenas e pessoas com deficiência, com um total mínimo de vagas com a mesma proporção da quantidade populacional destas minorias da unidade federativa que a instituição está situada, conforme o Instituto Brasileiro de Geografia e Estatística/IBGE (BRASIL, 2012).

\title{
A REDE FEDERAL
}

A Rede Federal de Educação Profissional, Científica e Tecnológica foi criada em 1909, pelo então presidente da República, Nilo Peçanha, por meio do Decreto no 7566/1909:

\begin{abstract}
Considerando: que o aumento constante da população das cidades exige que se facilite às classes proletárias os meios de vencer as dificuldades sempre crescentes da luta pela existência: que para isso se torna necessário, não só habilitar os filhos dos desfavorecidos da fortuna com o indispensável preparo técnico e intelectual, como fazelos adquirir hábitos de trabalho profícuo, que os afastara da ociosidade ignorante, escola do vício e do crime; Que é um dos primeiros deveres do Governo da Republica formar cidadãos uteis a Nação: Decreta: Art. $1^{\circ}$ Em cada uma das capitais dos Estados da Republica o Governo Federal manterá, por intermédio do Ministério da Agricultura, Industria e Commercio uma Escola de Aprendizes Artífices, destinada ao ensino profissional primário e gratuito (BRASIL, 2020).
\end{abstract}

Pelo então referido decreto, foram criadas 19 escolas de Aprendizes e Artífices que, posteriormente, foram os primeiros Centros Federais de Educação Profissional e Tecnológica (CEFETs) (BRASIL, 2020).

Em 29 de dezembro de 2008, foi aprovada a lei o․ 11.892/08, na qual transforma Centros Federais de Educação Tecnológica (CEFETs), unidades de ensino descentralizadas (UNEDs) escolas agrotécnicas e escolas técnicas federais bem como escolas vinculadas às universidades nos Institutos Federais de Educação, Ciência e Tecnologia. Os institutos federais são instituições de educação básica, profissional e tecnológica, pluricurriculares e multicampi. Oferecem educação profissional e tecnológica em várias modalidades de ensino, aliando conhecimentos

RC: 105315

Disponível em: https://www.nucleodoconhecimento.com.br/educacao/educacao-formalindigena 
técnicos e tecnológicos, formando e objetivando o profissional em várias áreas da economia com destaque no desenvolvimento econômico e social, regional e nacional (BRASIL, 2008).

Em 2020, a rede federal alcançou mais de um milhão de estudantes matriculados/as e 80 mil servidores/as. É composta por 38 Institutos Federais de Educação, Ciência e Tecnologia (IFs), Dois Centros Federais de Educação Tecnológica (Cefets); O Colégio Pedro II; Uma Universidade Tecnológica Federal; e 23 Escolas Técnicas Vinculadas às Universidades Federais. As instituições com seus respectivos campi totalizam 661 campi, distribuídos em todo o território nacional (IFFAR, 2021).

O processo de expansão da educação profissional e tecnológica (EPT), passou e vem passando por transformações, reconfigurações e incorporações institucionais. Compõem um programa que mesmo sofrendo críticas associando-o a ideias economicistas, trouxe consideráveis e visíveis benefícios para a sociedade onde atua. Este crescimento é dependente das políticas públicas para a educação e das fragilidades do cenário político (SOUZA e SILVA, 2016).

\section{OBJETIVO}

Discorrer sobre a educação formal indígena no âmbito da Educação Profissional e Tecnológica (EPT).

\section{MÉTODO}

Foi realizada uma pesquisa bibliográfica em língua portuguesa em bases de dados de pesquisa como Scientific Electronic Library Online - SciELO; Google Acadêmico; Biblioteca Digital Brasileira de Teses e Dissertações- BDTD; e periódicos CAPES (Portal da CAPES). 


\section{RESULTADOS E DISCUSSÕES}

\section{A POLÍTICA DE COTAS PARA ACESSO À EDUCAÇÃO}

A lei 12.711/2012, versa sobre a obrigatoriedade da reserva de vagas nas universidades e institutos federais, combinando frequência na escola pública com renda e etnia (BRASIL, 2012). Ela tem como objetivo maior promover o acesso à educação de qualidade e gratuita em instituições federais de ensino técnico de nível médio e superior à camadas da sociedade que, no passado, não tinham oportunidades (WANDROSKI e COLEN, 2014).Também definida como política de ações afirmativas, o sistema de cotas é utilizado como estratégia promocional, a fim de incentivar a inclusão de grupos vulneráveis, e proporcionar reparação, justiça distributiva e diversidade. As ações afirmativas podem ser classificadas como políticas públicas e privadas. A primeira decorrente de ações do poder executivo ou judiciário e ações que objetivam o combate à discriminação estabelecida pela iniciativa privada (TORRES et al., 2021).

Em um contexto histórico de políticas afirmativas, usadas como suporte para ações no Brasil, a exemplo do sistema norte americano, justifica-se por histórico semelhante de exploração por colônias europeias e utilização de escravos (WANDROSKI e COLEN, 2014). Na índia, se faz referência ao sistema de vagas para os dalits, os também conhecidos "intocáveis", o grupo mais discriminado do país. É o maior sistema já formulado, sendo inspiração para muitos países, construindo a igualdade a partir da diferença. Outros países também desenvolveram ações afirmativas, bem como: Malásia, Austrália, Canadá, Nigeria, África do Sul, Argentina, Cuba (MOEHLECKE, 2002).

A sociedade brasileira (multiétnica, com indígenas, brancos, negros e demais etnias) deve se fazer representada na decisão e implantação de políticas públicas educacionais. A participação de movimentos sociais é um elemento importante para a construção dessas políticas, sendo os povos indígenas parte de um dos segmentos

RC: 105315

Disponível em: https://www.nucleodoconhecimento.com.br/educacao/educacao-formalindigena 
que mais exigem do Estado ações que visem a construção dessas políticas. A implantação desse acesso deve considerar as diferenças socioculturais, políticas, demográficas e o mais importante seus processos próprios de educação (BANIWA, 2013).

Neste sentido, é importante referenciarmos que mesmo que a política de cotas tenha sido uma resposta positiva, sua implementação gerou questões polêmicas. A primeira questão é que se refere aos direitos indígenas como coletivos (onde a comunidade é o indivíduo). As instituições de ensino consideram o direito ao ingresso de forma individualizada, o que é considerado um risco ou ameaça aos seus princípios e modos de vida. Esta coletividade é responsável pela escolha dos candidatos e dos cursos de seu interesse, bem como, acompanhamento da formação e o retorno para a comunidade. Entretanto, o que se observa, em sua maioria, são indivíduos indígenas residentes em centros urbanos que não possuem compromisso com a comunidade se beneficiando com a atual política. A situação é agravada pela complexidade de acesso aos vestibulares e exames de acesso. Seria necessário atender, na mesma proporção, os indígenas que vivem nas comunidades, pois estes têm maior possibilidade de manter o compromisso de retornar a ela após finalizar o curso (BANIWA, 2013).

Existem desafios enfrentados pelos alunos indígenas diante da educação formal. É importante considerar a importância do nivelamento de conhecimentos e da sua adaptação ao mundo acadêmico. Isso traz a necessidade da existência de programas de acompanhamento e tutoria que dê Ihes assistência desde o acesso até a finalização dos cursos, com o intuito de diminuir a evasão (SOUZA et al., 2020). Disponibilizar cotas não é o suficiente. É também prioritário subsidiar projetos e programas, bem como, viabilizar bolsas de pesquisa que preservem a ligação do indivíduo com a sua comunidade. Torna-se interessante então proporcionar também ações pedagógicas com objetivo de reduzir a discriminação enfrentada por esses alunos (BANIWA, 2013).

RC: 105315

Disponível em: https://www.nucleodoconhecimento.com.br/educacao/educacao-formalindigena 
A lei de cotas representa uma etapa significativa, ainda que modesta, para inclusão e democratização ao acesso e permanência na educação. Para entendermos a realidade deste processo, é importante apresentar o contexto e os desdobramentos da política de reserva de vagas (KOSTRYCKI, 2020).

\section{A POLÍTICA DE COTAS E O INSTITUTO FEDERAL DO AMAPÁ (IFAP)}

O Instituto Federal de Educação, Ciência e Tecnologia do Amapá foi criado pela Lei № 11.892/2008, mesma lei que instituiu a Rede Federal de Educação Profissional, Científica e Tecnológica, a partir da Escola Técnica Federal do Amapá (ETFAP), instituída pela Lei no 11.534, de 25 de outubro de 2007 (RAMOFLY e MACEDO, 2020). Iniciou suas atividades no ano de 2010, com as unidades Macapá e Laranjal do Jari, com a oferta de cursos técnicos na modalidade Subsequente, disponibilizando 420 vagas (MIRANDA, 2021).

O Plano de Desenvolvimento Institucional (PDI) 2010-2014, norteado pelas ações afirmativas, obedecendo à lei 12.711/2012, sobre a implementação de cotas, teve $10 \%$ das vagas destinadas às cotas para negos e indígenas (IFAP, 2012). O gráfico exemplifica a distribuição do perfil do aluno do IFAP, por cor/raça, no ano de 2017.

RC: 105315

Disponível em: https://www.nucleodoconhecimento.com.br/educacao/educacao-formalindigena 
Gráfico 1: Distribuição do perfil do aluno do IFAP, por cor/raça, no ano de 2017.

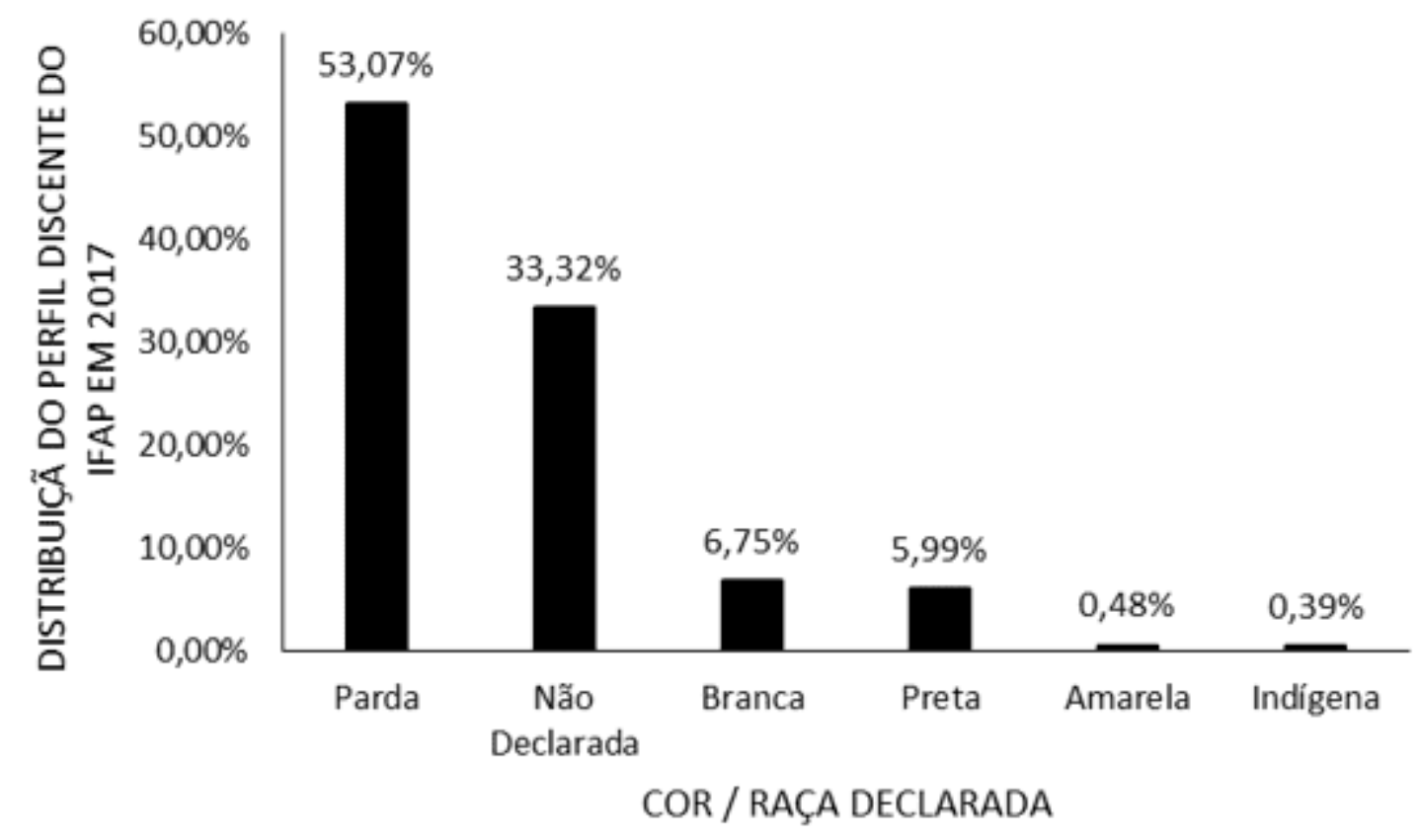

Fonte: Adaptado de IFAP (2019a)

Em seu PDI 2019, o IFAP tem como compromisso, até 2023, aumentar o percentual de vagas destinadas a alunos de escolas públicas, indígenas e quilombolas em seu processo seletivo (IFAP, 2019a).

Atualmente, o Instituto Federal do Amapá, prevê em seus editais de processo seletivo uma reserva de $50 \%$ de suas vagas destinadas às cotas (IFAP, 2021). As vagas estão previstas como reserva de vagas e não garantia. O estudante deve se enquadrar nos requisitos para a vaga e possuir os documentos comprobatórios para se classificar para a vaga (KOSTRYCKI, 2020). O processo seletivo para os cursos integrados, por exemplo, é realizado via análise documental (IFAP, 2021).

Aos candidatos que passam por todas as fases, tem pela frente outro desafio, permanecer na instituição e finalizar o curso, estes representam os demais alunos que

RC: 105315

Disponível em: https://www.nucleodoconhecimento.com.br/educacao/educacao-formalindigena 
não tiveram oportunidade de acesso. A instituição cabe promover condições para permanência e saída exitosa (KOSTRYCKI, 2020).

\section{NÚCLEO DE ESTUdOS AFRO-BRASILEIROS E INDÍGENAS - NEABI/IFAP}

O núcleo tem natureza propositiva, consultiva, vinculado à Pró-reitoria de Extensão, Pesquisa, Pós-Graduação e Inovação. Tem a função de auxiliar no direcionamento de estudos, estimular e promover ações de ensino, pesquisa e extensão que promovam a reflexão sobre as temáticas das identidades e das relações étnico-raciais, referente às questões da diversidade na perspectiva dos princípios multiculturais, tendo como escopo o fomento a estudos e desenvolvimento de ações de valorização das identidades afro e indígenas, no âmbito da instituição e em suas relações com a comunidade externa (IFAP, 2019b).

\section{O INDÍGENA NO ÂMBITO DA EDUCAÇÃO PROFISSIONAL E TECNOLÓGICA}

A construção de cursos de educação profissional integrada à educação escolar indígena deve considerar os impasses, como também as potencialidades, na relação entre conhecimentos e práticas indígenas e os conhecimentos técnico-científicos, bem como a possibilidade de que os povos indígenas venham realmente a neles inscrever a sua própria perspectiva (BRASIL, 2007).

Para SANTOS e MÜLLING (2019), o problema reside em saber com que relação étnica se está tecnificando a mão de obra, quando o objetivo de dirimir a fome está em uma atitude moderna útil e rentável, econômica e divorciada de uma ética interna e cultural, de um projeto coletivo étnico e sustentável e fortalecido. Visto que, reconhecido o direito constitucional aos processos próprios de existência indígena, é

RC: 105315

Disponível em: https://www.nucleodoconhecimento.com.br/educacao/educacao-formalindigena 
legítima a sua resistência à inserção no mundo capitalista legitimando a sua luta por caminhar na construção de espaços alternativos ao sistema universalista vigente.

\begin{abstract}
Sua reexistência trata-se da reconfiguração da vida indígena em diálogo com o mundo, do movimento do que é mutável e imutável na cultura, sob a perspectiva de seus sujeitos. Além disso, não se trata meramente de pedir acesso às vantagens dos avanços do ocidente mediante acesso à educação, nem de demonstrar que a sabedoria indígena detém também caráter científico, mas de demarcar a vigência das culturas indígenas na vida cotidiana da população latino americana em uma perspectiva descolonial. (SANTOS e MÜLLING, 2019).
\end{abstract}

As necessidades da educação profissional indígenas são permeadas por políticas institucionais e seu êxito passa por adaptações curriculares como, por exemplo, uso da oralidade em avaliações (ESTEVÃO e BARBOSA, 2021). A pressão para a exploração capitalista dos territórios indígenas hoje é incessante, seja para mineração, para obtenção de recursos naturais, como madeira e pesca, seja para a locação de terras indígenas para o agronegócio. Em todas as regiões do país, os indígenas têm sido assediados, em virtude da falta de alternativas, por agentes do modelo de desenvolvimento econômico predador. Vide a ser necessário, o apoio aos povos indígenas para que eles encontrem alternativas sustentáveis de gerenciamento autônomo de seus territórios (SILVA, 2018).

A população indígena no Brasil é expressiva e precisa-se discutir o acesso à educação desses povos. Garantir não somente o seu acesso, mas também a permanência e êxito dos estudantes. $O$ último censo realizado registra que a parcela da população que se declararam da cor ou raça indígena foi de 896.817 mil pessoas, representando $0,4 \%$ da população brasileira no ano da referida pesquisa. Isso demonstra a grande importância de se estudar e discutir a educação indígena (IBGE, 2012).

Em pesquisa feita no banco de dados Capes, o ensino médio técnico indígena constitui temática escassa e recente, visto que sua perspectiva pode ser associada à expansão da Rede Federal de Educação, Ciência e Tecnologia, iniciada em 2008, sendo assim, uma área de amplas demandas políticas e acadêmicas. A disseminação RC: 105315

Disponível em: https://www.nucleodoconhecimento.com.br/educacao/educacao-formalindigena 
e aprofundamento dos estudos na área se faz importante para a construção e consolidação dos direitos à educação dos povos originários (MULLING e SANTOS, 2016).

\title{
BUSCA PELA QUALIFICAÇÃO POR ESSES POVOS.
}

No Brasil, encontramos uma grande diversidade de processos de escolarização vivenciados pelos povos indígenas. Povos que já possuem uma longa experiência com educação formal ofertada por agências governamentais e não-governamentais, outros a iniciaram mais recentemente e outros ainda resistem em aceitar a escola que Ihes é oferecida em suas comunidades, temendo o impacto dessa ação sobre a organização tradicional dos processos de aprendizagem e de educação dos sujeitos indígenas (BRASIL, 2007).

Uma qualificação educacional que busque não somente a sua inclusão no mundo dos não-indígenas, mas que o prepare para a sua relação com o mundo externo longínquo da comunidade indígena, uma formação capaz de prepará-lo para dentro e fora do seu contexto local (DOWBOR, 2007)

\begin{abstract}
A ideia da educação para o desenvolvimento local está diretamente vinculada a esta compreensão, e à necessidade de se formar pessoas que amanhã possam participar de forma ativa das iniciativas capazes de transformar o seu entorno, de gerar dinâmicas construtivas. Hoje, quando se tenta promover iniciativas deste tipo, constata-se que não só os jovens, mas inclusive os adultos desconhecem desde a origem do nome da sua própria rua até os potenciais do subsolo da região onde se criaram. Para termos cidadania ativa, temos de ter uma cidadania informada, e isto começa cedo. A educação não deve servir apenas como trampolim para uma pessoa escapar da sua região: deve dar-lhe os conhecimentos necessários para ajudar a transformá-la (DOWBOR, 2007).
\end{abstract}

Neste sentido, se faz importante a discussão a respeito das metodologias utilizadas com os povos indígenas, as políticas públicas e institucionais de assistência para a inclusão, permanência e êxito do estudante indígena. Uma educação escolar intercultural, considerando a realidade e os saberes construídos historicamente pela

RC: 105315

Disponível em: https://www.nucleodoconhecimento.com.br/educacao/educacao-formalindigena 
comunidade indígena, tornam 0 processo de ensino e aprendizagem mais significativos, aproximando as disciplinas formais ofertadas com o cotidiano. A interculturalidade deve contribuir para superar divergências quanto à convivência com o diferente, facilitando a relação com a pluralidade social e cultural, sendo fundamentais para a formação de todos os alunos indígenas e não-indígenas. É importante romper com o padrão de ensino imposto e construir estratégias que aproximem a educação escolar que valorize os saberes tradicionais. (SILVA e FELZKE, 2021).

\section{CONCLUSÕES}

A educação parece ser o caminho para a integração do indígena e sua formação para benefício próprio e da comunidade. Isso provavelmente faria com que o indígena tivesse oportunidades parecidas com as que têm os não indígenas.

A política de cotas ou de ações afirmativas é uma tentativa de diminuir a distância social quando se fala do acesso a vagas na educação, inclusive técnica. Tratar diferente quem é diferente talvez auxilie, no futuro, a existência de uma sociedade mais igualitária.

A existência de núcleos de estudos afro-brasileiros e indígenas parece, ainda que timidamente, contribuir com a pesquisa e divulgação sobre identidades e relações étnico-raciais, visando a diminuição da distância socioeducacional e das diferenças dentro das instituições.

Apesar do preparo, ainda que em construção, das instituições para atender um público diverso como os indígenas, o acesso destes ainda é considerado pequeno, em um estado como, por exemplo, o Amapá. Para atrair o aluno indígena seria necessária uma divulgação mais ampla e mais próxima da realidade das comunidades indígenas, inclusive respeitando a cultura diferenciada deles, onde a comunidade funciona como se fosse um indivíduo.

RC: 105315

Disponível em: https://www.nucleodoconhecimento.com.br/educacao/educacao-formalindigena 


\section{REFERÊNCIAS}

BANIWA, G. A Lei das Cotas e os povos indígenas: mais um desafio para a diversidade. Cadernos do Pensamento Crítico Latino-Americano, n. 34, p. 1821, 2013.

BRASIL. CONSTITUIÇÃO DA REPÚBLICA FEDERATIVA DO BRASIL DE 1988. Brasilia DF, $1988 . \quad$ Disponível em: < https://www.planalto.gov.br/ccivil_03/constituicao/constituicao.htm >. Acesso em: 21 mai 2021.

. LEI № 9.394, DE 20 DE DEZEMBRO DE 1996. Brasilia DF, 1996.Disponível em: < http://www.planalto.gov.br/ccivil_03/leis/L9394compilado.htm >. Acesso em: 21 mai 2021.

. Diretrizes Curriculares Nacionais da Educação Escolar Indígena. Brasilia

DF, 1999.

Disponível em:

$<$ http://portal.mec.gov.br/cne/arquivos/pdf/1999/pceb014_99.pdf >. Acesso em: 21 mai 2021.

. LEI Nº10172, DE 9 DE JANEIRO DE 2001. Brasilia DF, 2001. Disponível em: < http://portal.mec.gov.br/arquivos/pdf/L10172.pdf >. Acesso em: 14 mai 2021.

. PROEJA - Programa Nacional de Integração da Educação Profissional com A Educação Básica na Modalidade de Educação de Jovens e Adultos. Brasília SP, $2007 . \quad$ Disponível em: < http://portal.mec.gov.br/setec/arquivos/pdf2/proeja_medio.pdf >. Acesso em: 05 mai 2021.

. LEI № 11.892, DE 29 DE DEZEMBRO DE 2008. Brasilia DF: Casa Civil 2008.

. LEI № 12.711, DE 29 DE AGOSTO DE 2012. Brasilia DF: Casa Civil 2012.

RC: 105315

Disponível em: https://www.nucleodoconhecimento.com.br/educacao/educacao-formalindigena 
. DECRETO № 7.566, DE 23 DE SETEMBRO DE 1909. Brasília -

DF, 2020. Disponível em: < https://www2.camara.leg.br/legin/fed/decret/19001909/decreto-7566-23-setembro-1909-525411-publicacaooriginal-1-pe.html >. Acesso em: 05 mai 2020.

DOWBOR, L. Educação e apropriação da realidade local. Estudos Avançados, v. 21, n. 60, p. 75-90, 2007.

ESTEVÃO, F. L. B. S.; BARBOSA, X. C. Wari':Identidade E Diferença Na Composição Da Educação Profissional E Tecnológica No Instituto Federal De Rondônia. Educação Profissional e Tecnológica em Revista, v. 5, p. 99-123, 2021.

IBGE. Censo 2010: população indígena é de 896,9 mil, tem 305 etnias e fala 274 idiomas. Rio de Janeiro RJ, 2012. Disponível em: < https://censo2010.ibge.gov.br/noticias-

censo ?busca=1\&id=3\&idnoticia=2194\&view=noticia >. Acesso em: 05 mai 2020.

IFAP. Plano De Desenvolvimento Institucional. Macapá AP, 2012. Disponível em: < http://www.siteantigo.ifap.edu.br/index.php?option=com_docman\&task=cat_view\&gid $=121 \&$ Itemid $=66>$.

. Plano de Desenvolvimento Institucional. Macapá AP, 2019a. Disponível em: < https://ifap.edu.br/index.php/quem-somos/pdi >. Acesso em: 13 jan 2022.

\section{. RESOLUÇÃO № 123/2019/CONSUP/IFAP, DE 12 DE DEZEMBRO DE} 2019. Macapá AP: CONSUP/IFAP: 1-5 p. 2019b.

. EDITAL IFAP PROEN № 10/2021. Macapá AP, 2021. Disponível em: < https://ifap.edu.br/index.php/publicacoes/item/3872-edital-10-2021-proen-integrado2022-1 >. Acesso em: 17 jan 2022.

RC: 105315

Disponível em: https://www.nucleodoconhecimento.com.br/educacao/educacao-formalindigena 
IFFAR. Rede Federal completa 112 anos! , Santa Maria RS, 2021. Disponível em: < https://iffarroupilha.edu.br/noticias-jaguari/item/23223-rede-federal-completa-112anos >. Acesso em: 05 jan 2022.

KOSTRYCKI, X. M. Para Além Do Acesso: A Política De Cotas E O Abandono Escolar No Instituto Federal Do Paraná, Campus Paranaguá. 2020. 104p. (Mestrado). Instituto Federal do Paraná, Curitiba PR.

MENDES, M.; OLIVEIRA, N.; VALENTE, H. Atuação docente na diversidade. Pará de Minas, MG: VirtualBooks, 2017. 85p.

MIRANDA, L. D. V. A. METODOLOGIA ATIVA: analisar o papel do projeto integrador no processo ensino/aprendizagem dos alunos dos cursos técnicos na modalidade subsequente do Instituto Federal de Educação, Ciências e Tecnologia no município de Oiapoque-AP. 2021. 29p. (Graduação). IFAP, Oiapoque AP.

MOEHLECKE, S. Ação Afirmativa: História E Debates No Brasil. Cadernos de Pesquisa, n. 117, p. 197-217, 2002.

MULLING, J. D. C.; SANTOS, S. V. D. Educação Escolar Indígena: levantamento das pesquisas sobre Ensino Médio e Ensino Técnico. Curitiba - PR: UFPR: 1-16 p. 2016.

QUARESMA, F. J. P.; FERREIRA, M. N. Os povos indígenas e a educação. Revista Práticas de Linguagens, v. 3, n. 2, p. 234-246, 2013.

RAMOFLY, B.; MACEDO, P. C. S. História e Memóriada Educação Profissional e Tecnológica: as narrativas do processo de implantação e expansão do Instituto Federal do Amapá. Revista Labor, v. 2, n. 24, p. 372-395, 2020. 
RIBEIRO, D. Os índios e a civilização. Rio de Janeiro RJ: Círculo do Livro, 1989. 460p.

SANTOS, S. V.; MÜLLING, J. C. A presença de estudantes indígenas na educação profissional e tecnológica. Educação, v. 42, n. 3, p. 475-485, 2019.

SILVA, E. C. A. Povos indígenas e o direito à terra na realidade brasileira. Serv. Soc. Soc., n. 133, p. 480-500, 2018. Disponível em: < https://www.scielo.br/j/sssoc/a/rX5FhPH8hjdLS5P3536xgxf/?lang=pt >.

SILVA, M. A. X.; FELZKE, L. F. Aspectos Culturais E Metodológicos No Processo De Aprendizagem Dos Estudantes Indígenas Macuxi: Experiências Do Instituto Federal De Roraima Campus Amajari. v. 5, p. 77-98, 2021.

SOUZA, F. C. S.; SILVA, S. H. S. C. Institutos Federais: Expansão, Perspectivas E Desafios. Revista Ensino Interdisciplinar, v. 2, n. 5, p. 17-26, 2016.

SOUZA, K. C. B. D. et al. Evasão escolar no Ensino Médio Integrado da Rede Federal de Educação nas capitais da Região Norte, Brasil (2014-2018). Research, Society and Development, v. 9, n. 8, p. 1-13, 2020.

TORRES, L. O.; DIAS, J. C.; FILHO, J. C. M. B. Ações afirmativas como instrumento de promoção da igualdade de recursos: o caso do programa de trainee exclusivo para negros do Magazine Luiza. Revista de Direito, v. 13, n. 3, p. 01-24, 2021.

WANDROSKI, S. F.; COLEN, F. R. C. As ações afirmativas para ingresso de estudantes no Instituto Federal de Educação, Ciência e Tecnologia de Rondônia. 0 Social em Questão, n. 32, p. 165-182, 2014.

Enviado: Janeiro, 2022.

Aprovado: Janeiro, 2022.

RC: 105315

Disponível em: https://www.nucleodoconhecimento.com.br/educacao/educacao-formalindigena 